\title{
Binding of glycosaminoglycans to the surface of Treponema pallidum and subsequent effects on complement interactions between antigen and antibody
}

\author{
T J FITZGERALD,* J N MILLER, † L A REPESH, $\$$ M RICE,* AND \\ A URQUHART $\uparrow$ \\ From the *Department of Medical Microbiology and Immunology and the ₹Department of Biomedical \\ Anatomy, UMD School of Medicine, Duluth, Minnesota 55812, and the +Department of Microbiology \\ and Immunology, UCLA School of Medicine, Los Angeles, California 90024, USA
}

SUMMARY Acidified bovine serum albumin (acid BSA) reacts with glycosaminoglycans to form a precipitate. This reaction was adapted to Treponema pallidum to show glycosaminoglycans associated with the surface of the micro-organism. As testicular infection progressed from days 4 to 18, treponemes showed increasing amounts of these surface components. High speed centrifuging effectively removed the glycosaminoglycans, thus indicating that they were loosely bound. The subsequent addition of commercial preparations of hyaluronic acid or chondroitin sulphate resulted in their immediate adherence to the surface of the pathogens $T$ pallidum and $T$ pertenue, but not to the non-pathogens $T$ vincenti, $T$ denticola, or $T$ phagedenis. The amount adhering to the treponemal surface varied depending on the concentration added. Intradermal inoculation showed that the virulence of $T$ pallidum was not altered by the glycosaminoglycans associated with its surface. The coating of treponemes with hyaluronic acid or chondroitin sulphate did not interfere with neutralising antibodies or antibodies found by radioimmunoassay using whole organisms. In contrast, hyaluronic acid or chondroitin sulphate on the treponemal surface did interfere with immobilising antibodies. Results are discussed in terms of the potential role of the treponemal glycosaminoglycans in the infectious process.

\section{Introduction}

Freshly isolated Treponema pallidum used as antigen in the $T$ pallidum immobilisation (TPI), $T$ pallidum agglutination (TPA), fluorescent treponemal antibody absorbed (FTA-ABS), and neutralisation tests requires an "ageing" process to maximise reactivity with antibodies. The organism seems to have an outer labile layer that must be altered or removed before seroreactivity. ${ }^{1-7}$ Von Schmerold and Deubner $^{8}$ and Swain ${ }^{9}$ showed a structure like a capsule at the surface of $T$ pallidum. This material reacts with both ruthenium red $^{1011}$ and acidified bovine serum albumin (acid BSA), ${ }^{12} 13$ which suggests that it is hyaluronic acid, chondroitin sulphate, or a

Address for reprints: Dr T J Fitzgerald, Department of Medical Microbiology and Immunology, University of Minnesota School of Medicine, Duluth, Minnesota 55812, USA

Accepted for publication 12 May 1984 similar glycosaminoglycan (formerly called mucopolysaccharide ${ }^{1012}$ ).

It has been proposed that glycosaminoglycans have an excluded volume that limits penetration of antibodies to bacterial surfaces. ${ }^{14}$ The treponemal labile layer responsible for blocking antigen and antibody reactions may partly consist of glycosaminoglycans. These components are highly soluble in water and might possibly gradually dissipate from the treponemal surface during in vitro incubation. Preliminary experiments showed that high speed centrifuging effectively removed the glycosaminoglycans associated with the treponemal surface. The subsequent addition of commercial preparations of hyaluronic acid or chondroitin sulphate resulted in their immediate adherence to the treponemal surface. The purpose of this report was to extend these preliminary findings and to assess whether a coating of glycosaminoglycans interfered with reactions between antigen and antibody. 


\section{Materials and methods}

\section{TREPONEMES}

The Nichols strain of $T$ pallidum was maintained by intratesticular passage in Dutch Belt or New Zealand White rabbits. The animals were housed at $18^{\circ} \mathrm{C}$ to $20^{\circ} \mathrm{C}$ and given food free of antibiotics and water ad libitum. About $10 \times 10^{6}$ to $30 \times 10^{6}$ treponemes were inoculated per testis. Animals were injected daily with cortisone acetate (Merck Sharpe and Dohme, Westpoint, Pensylvania, USA) $6 \mathrm{mg} / \mathrm{kg}$ body weight starting three days after infection. All experiments except TPI tests were performed with treponemes isolated from rabbits treated with cortisone. Animals were killed on days 8 to 10 by intracardiac injection of pentabarbitol. The testes were removed, rinsed in saline, and extracted aerobically in McCoy's medium containing $1 \mathrm{mmol} / 1$ dithiotreitol, $30 \mathrm{mmol} / \mathrm{l} \mathrm{N}$-2-hydroxethylpiperazine$\mathrm{N}^{1}$-2-ethanesulphonic acid (HEPES) buffer, and $10 \%$ rabbit serum (heated to $56^{\circ} \mathrm{C}$ for 30 minutes). After 25 minutes, the preparation was centrifuged at $1000 \times g$ for 10 minutes to sediment particulate matter (slow speed centrifuging). In some experiments the supernatant containing the treponemes was then centrifuged at $18000 \times g$ for 30 minutes at $4^{\circ} \mathrm{C}$ (high speed centrifuging). The pelleted organisms were then resuspended in fresh medium. For all experiments except TPI tests, incubation was performed at $37^{\circ} \mathrm{C}$ in an atmosphere of $5 \%$ carbon dioxide, $2 \cdot 5 \%$ oxygen, and $92 \cdot 5 \%$ nitrogen. For TPI tests $5 \%$ carbon dioxide, $95 \%$ nitrogen was used.

$T$ pertenue was provided by Dr Ronald Schell of Hahnemann Medical College. The organisms were grown intratesticularly in rabbits not injected with cortisone and they were harvested as described for $T$ pallidum after 20 to 30 days. $T$ vincenti, $T$ denticola, and $T$ phagedenis were supplied by $\mathrm{Dr}$ Russell $\mathrm{C}$ Johnson of the University of Minnesota. These three non-pathogenic species were grown in the modified medium of Livermore and Johnson ${ }^{15}$ in an atmosphere of $5 \%$ carbon dioxide and $95 \%$ nitrogen at $37^{\circ} \mathrm{C}$. Organisms were used when they were in the mid-logarithmic growth phase. ${ }^{16}$

\section{DISCLOSURE OF GLYCOSAMINOGLYCAN}

Hyaluronic acid and chondroitin sulphate react with acid BSA by forming a precipitate. ${ }^{17} 18$ To acidify the BSA, $1 \mathrm{ml}$ of $10 \% \mathrm{BSA}$ (wt/vol) in physiological saline was added to $0.4 \mathrm{ml}$ of $2 \mathrm{~mol} / 1$ acetic acid (pH 4). As described previously, ${ }^{12} 13$ about $10 \mu \mathrm{l}$ treponemal suspension and $10 \mu \mathrm{l}$ acid BSA were taken up into a capillary tube and mixed by inverting the tube five times. A drop was placed on a slide and studied using dark field microscopy. The presence of precipitate on at least 50 organisms was then recorded and expressed as a percentage of total organisms.

\section{RABBIT LESIONS}

To test neutralisation and virulence, the clipped backs of female animals giving no reactions to rapid plasma reagin (RPR) circle card tests were inoculated intradermally at duplicate sites with $0.1 \mathrm{ml}$ treponemal suspension. During the study period, the animals were clipped when necessary. After the development of typical lesions, samples were taken from them and examined by dark field microscopy for actively motile treponemes.

\section{SERUM SAMPLES}

Normal serum was obtained from three to five uninfected animals that gave no reactions to RPR circle card tests. Immune rabbit serum was obtained from eight rabbits that had been infected three to 24 months previously and were shown to be immune by their resistance to challenge infection with $100 \times 10^{6}$ organisms. Serum samples were heat inactivated at $56^{\circ} \mathrm{C}$ for 30 minutes when necessary.

\section{ANTIBODY TESTS}

Each of these tests was performed with treponemes incubated with $250 \mathrm{mg} / 1$ hyaluronic acid or chondroitin sulphate, or with medium alone. The TPI test was performed on immune rabbit serum from eight different rabbits; the end point was defined as the highest dilution at which $50 \%$ of the treponemes were immobilised. ${ }^{19} \mathrm{~A}$ modified immobilisation test was also used in which the organisms were suspended in the described extraction medium, the source of complement was normal rabbit serum, the test serum concentration was $40 \%$, incubation was performed in $2.5 \%$ oxygen, and motility was observed until all preparations were non-motile. The neutralisation test of Bishop and Miller ${ }^{1}$ was also slightly modified. The organisms were suspended in extraction medium, the test serum concentration was $50 \%$, and incubation was performed in $2.5 \%$ oxygen. Radioimmunoassay was performed as described by Zeltzer $e t a l^{20}$ and Pepose et $a l^{21}$ using heated immune rabbit serum as a source of antibodies.

\section{SCANNING ELECTRON MICROSCOPY}

Treponemes were incubated with cultured cells derived from rabbit testicular tissue for two hours in Sykes-Moore chambers. ${ }^{22}$ The cultures were then washed three times with phosphate buffered saline (PBS). This technique of attaching organisms to cells facilitates fixation and processing for electron microscopy. ${ }^{23}$ Cetyl pyridinium chloride (CPC) forms a heavy precipitate in the presence of glycosaminoglycans. ${ }^{24}$ CPC $0.4 \%$ was added during fixation with 
glutaraldehyde; controls were fixed in glutaraldehyde without CPC.

\section{CHEMICALS}

Hyaluronic acid from human umbilical cord, chondroitin sulphate from whale cartilage, and bovine albumin fraction $\mathrm{V}$ were bought from Sigma Co (St Louis, Missouri, USA). All other chemicals were reagent grade.

\section{Results}

The addition of acid BSA to freshly harvested $T$ pallidum resulted in variable quantities of precipitate associated with the surface of the organisms. Variations occurred from rabbit to rabbit. With some treponemal preparations almost all organisms were heavily coated; with other preparations half the organisms were coated; with still others, little or no acid BSA precipitate was seen. After organisms were centrifuged at high speed, repeat acid BSA reactions indicated that surface glycosaminoglycans were effectively removed. Identical findings were apparent with $T$ pertenue; variable quantities of acid BSA positive material were found on the treponemal surface, and high speed centrifuging effectively removed this material.

To investigate whether variations in the amount of glycosaminoglycans were related to the duration of infection, rabbits were infected intratesticularly with $T$ pallidum and killed at various times after infection. Cortisone injections enhance the accumulation of mucoid material within infected tissue, ${ }^{67}$ 25-27 and 40 animals were therefore injected daily with cortisone and 30 were not. Eight animals injected with cortisone and six not injected were killed each time. Treponemes were extracted from each rabbit separately. Table I summarises the averages of acid BSA reactions after slow speed centrifuging. Small amounts of treponemal glycosaminoglycans were present with and without cortisone four and seven days after

TABLE I Acid BSA reactions using $T$ pallidum isolated on different days after testicular infection

\begin{tabular}{lll}
\hline & \multicolumn{2}{l}{$\begin{array}{l}\text { Mean }(S E M) * \% \\
\text { with acid BSA }\end{array}$} \\
\cline { 2 - 3 } Days after infection & Without cortisone & With cortisone \\
\hline 4 & $4(1 \cdot 0)$ & $7(0 \cdot 8)$ \\
7 & $10(1 \cdot 9)$ & $14(1 \cdot 5)$ \\
10 & $38(4 \cdot 7)$ & $95(2 \cdot 7)$ \\
11 & $60(5 \cdot 1)$ & $91(2 \cdot 9)$ \\
12 & $84(6 \cdot 2)$ & $90(3 \cdot 6)$ \\
18 & & \\
\hline
\end{tabular}

BSA = bovine serum albumin.

*Standard error of the mean for six rabbits/day of infection without cortisone and eight rabbits/day of infection with cortisone. infection. Thereafter, noticeable increases were seen, with slightly higher readings in the animals treated with cortisone. Readings were $38 \%$ to $84 \%$ without cortisone, and $90 \%$ to $95 \%$ with cortisone. In general, more precipitate per individual organism was found in preparations from rabbits injected with cortisone.

As an alternative procedure to acid BSA reactions and dark field microscopy, the organisms were exposed to CPC and examined by scanning electron microscopy. ${ }^{24}$ Treponemes were harvested four or 12 days after infection. The figure shows that surface precipitate was not seen on treponemes after four days (a), but large amounts of precipitate were uniformly distributed along the surfaces of treponemes after 12 days (b). In control preparations not exposed to CPC (c) treponemes on day 12 did not contain detectable precipitate.

High speed centrifuging of treponemes and their resuspension in fresh medium was then used in all subsequent experiments. This step removes both the glycosaminoglycans bound to the treponemes and the soluble glycosaminoglycans present within the testicular extract. $T$ pallidum and $T$ pertenue were centrifuged at slow speed and then at high speed to remove acid BSA positive material. $T$ vincentii, $T$ denticola, and $T$ phagedenis were also centrifuged at high speed. Organisms were resuspended in medium containing hyaluronic acid and chondroitin sulphate at concentrations of $0,31,62,125$, and $250 \mathrm{mg} / \mathrm{l}$, and acid BSA tests were performed immediately. This experiment was repeated six times, and table II shows the average results. Hyaluronic acid and chondroitin sulphate bound to both $T$ pallidum and $T$ pertenue. Different quantities of glycosaminoglycans were seen, depending on the amount of hyaluronic acid or chondroitin sulphate added to the suspension medium. In 72 hours, some hyaluronic acid or chondroitin sulphate dissipated from the treponemal surface. In contrast, neither hyaluronic acid nor chondroitin sulphate was bound to the surface of any of the three non-pathogenic treponemes.

TABLE II Adherence of hyaluronic acid (HA) and chondroitin sulphate (CS) to the surface of treponemes

\begin{tabular}{|c|c|c|c|c|}
\hline \multirow{3}{*}{$\begin{array}{l}\text { Concentration } \\
(m g / l)\end{array}$} & \multicolumn{4}{|c|}{$\begin{array}{l}\text { Mean }(S E M) * \% \text { of treponemes reacting with } \\
\text { acid } B S A\end{array}$} \\
\hline & \multicolumn{2}{|c|}{ Treponema pallidum } & \multicolumn{2}{|c|}{ Treponema pertenue } \\
\hline & $H A$ & $C S$ & $H A$ & $C S$ \\
\hline $\begin{array}{r}0 \\
31 \\
62 \\
125 \\
250\end{array}$ & $\begin{array}{c}0(0) \\
16(2 \cdot 1) \\
90(5 \cdot 4) \\
93(2 \cdot 9) \\
100(1 \cdot 8)\end{array}$ & $\begin{array}{c}0(0) \\
0(0) \\
42(4 \cdot 5) \\
74(6 \cdot 5) \\
100(1 \cdot 2)\end{array}$ & $\begin{array}{r}0(0 \cdot 2) \\
10(0 \cdot 8) \\
44(3 \cdot 9) \\
67(9 \cdot 7) \\
75(6 \cdot 3)\end{array}$ & $\begin{array}{r}0(0 \cdot 1) \\
25(3 \cdot 5) \\
50(5 \cdot 6) \\
60(4 \cdot 3) \\
80(8 \cdot 7)\end{array}$ \\
\hline
\end{tabular}

BSA = bovine serum albumin.

*Standard error of the mean of three experiments. 

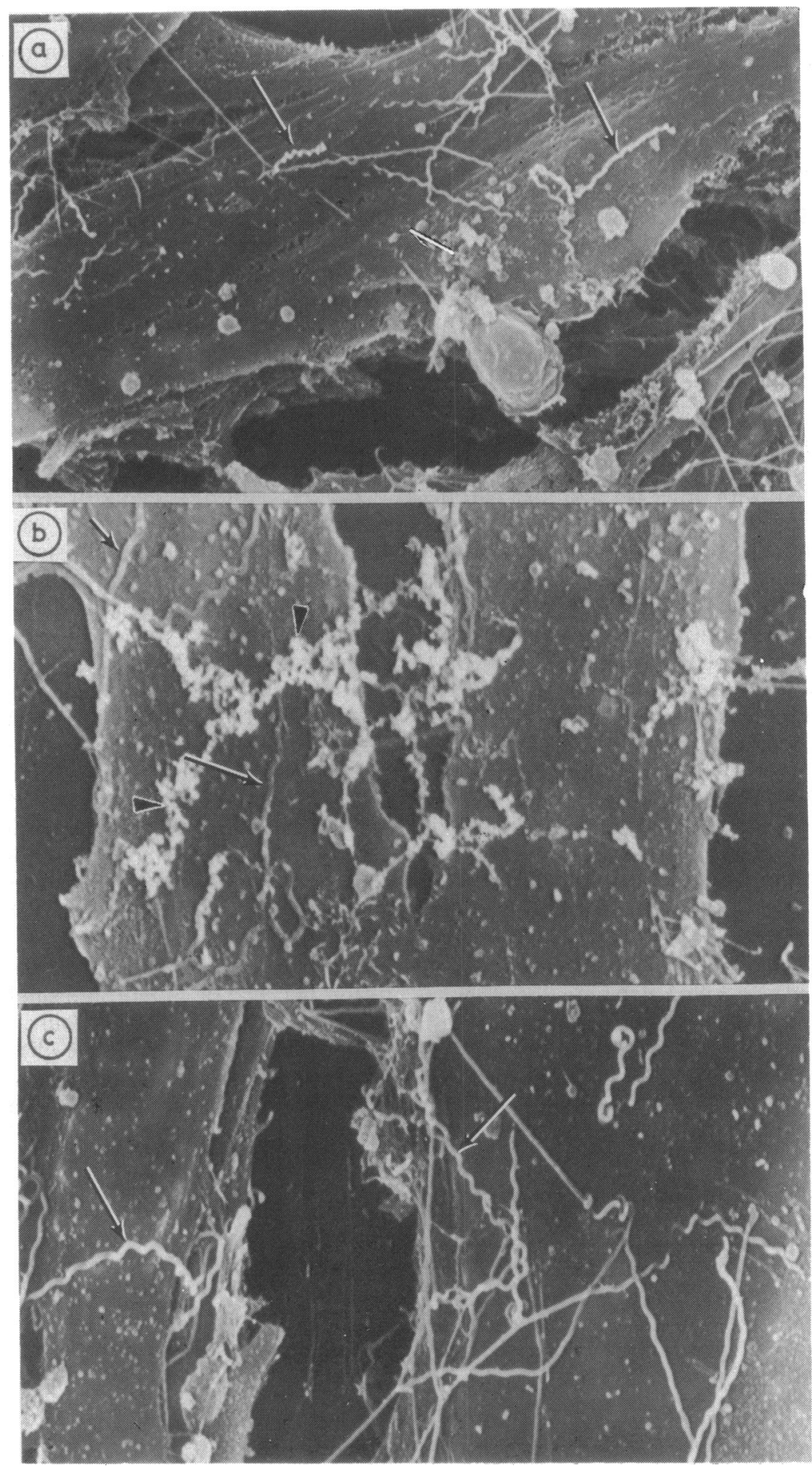

FIGURE Reactivity of treponemes with cetyl pyridinium chloride (CPC):

(a) day 4 non-reactive organisms exposed to $C P C$; (b) day 12 reactive organisms exposed to CPC; and (c) day 12 organisms as controls, not exposed to CPC.

(Arrows indicate non-reactive organisms; arrowheads indicate reactive organisms.) 
Rabbit testicular tissue contains relatively large amounts of hyaluronic acid. ${ }^{28}$ The inability to detect hyaluronic acid bound to treponemes four and seven days after infection may be attributed to "receptors" that may not develop until later in infection. To investigate this possibility, treponemes were isolated from infections at day $\mathbf{4}$ and centrifuged at high speed. The organisms were incubated with hyaluronic acid or chondroitin sulphate at $0,31,62$, 125 , and $250 \mathrm{mg} / \mathrm{l}$ and then assessed for acid BSA reactions. Results closely similar to those in table II were recorded, which indicated that these "younger" organisms also bound glycosaminoglycans.

In the next series of experiments we investigated glycosaminoglycan binding to non-viable organisms. After high speed centrifugation, samples of resuspended organisms were divided in two, and one portion was heat inactivated (at $56^{\circ} \mathrm{C}$ for 10 minutes). Hyaluronic acid and chondroitin sulphate at concentrations of $0,31,62,125$, and $250 \mathrm{mg} / \mathrm{l}$ were then added. Heating did not affect the binding of hyaluronic acid or chondroitin sulphate. Similar amounts of each glycosaminoglycan were seen in both the heated and the viable preparations.

We then compared the virulence of treponemal preparations containing variable amounts of hyaluronic acid and chondroitin sulphate associated with the surface of the treponemes. Freshly harvested organisms were centrifuged at high speed to remove endogenous glycosaminoglycans, and numbers were adjusted to $2 \times 10^{6}, 2 \times 10^{5}$, and $2 \times 10^{4}$ organisms $/ \mathrm{ml}$. Hyaluronic acid or chondroitin sulphate was added at concentrations of $0,31,61$, 125 , and $250 \mathrm{mg} / \mathrm{l}$ to yield a range of surface coating. These preparations were immediately injected intradermally into a total of 240 sites on 24 rabbits. Subsequent incubation periods, progression of lesions, and sites infected out of sites inoculated were recorded. At all three treponemal concentrations, neither hyaluronic acid nor chondroitin sulphate increased or decreased the virulence. In the control, as well as in each of the four hyaluronic acid and four chondroitin sulphate preparations, the incubation periods, total sites positive, and progression of lesions were closely similar.

Various antibody reactions were then tested to ascertain whether a coating of hyaluronic acid or chondroitin sulphate interfered with antibody binding to treponemal antigens. Neutralisation ${ }^{1}$ was tested using two different concentrations of $T$ pallidum in the presence or absence of hyaluronic acid or chondroitin sulphate at $250 \mathrm{mg} / \mathrm{l}$. Table III shows the results after a total of 192 sites on 16 rabbits had been injected intradermally. Comparison of the normal and immune rabbit serum preparations without glycosaminoglycans showed neutralisation. Incubation periods were lengthened and fewer sites developed lesions. Neither hyaluronic acid nor chondroitin sulphate influenced this neutralising effect. Incubation periods, sites positive out of sites injected, and progression of lesions were similar for immune serum preparations exposed to medium alone or to hyaluronic acid or chondroitin sulphate.

We also investigated the effects on antibodies shown by radioimmunoassay. ${ }^{20} 21$ These procedures required air drying of treponemes followed by fixing in ethanol. It was important to ensure that hyaluronic acid or chondroitin sulphate would coat these fixed organisms. Treponemes centrifuged at high speed and resuspended in fresh medium were air dried on a slide and fixed in ethanol. Hyaluronic acid or chondroitin sulphate $250 \mathrm{mg} / \mathrm{l}$ were placed on the slide, and acid BSA tests were performed. Both components coated these fixed organisms. Radioimmunoassay was then performed with fixed treponemes exposed to $250 \mathrm{mg} / 1$ hyaluronic acid or chondroitin sulphate, or medium alone, then incubated with heated normal rabbit serum or with heated immune rabbit serum as a source of antibodies. In the controls, which contained medium alone, much higher counts were found in the immune rabbit serum than in the normal rabbit serum wells, indicating the effectiveness of this assay in showing treponemal antigens. Treatment of the fixed

TABLE III Neutralisation by immune rabbit serum (IRS) in presence of hyaluronic acid (HA) and chondroitin sulphate (CS)

\begin{tabular}{|c|c|c|c|c|}
\hline \multirow[b]{2}{*}{ Preparation } & \multicolumn{2}{|c|}{ Concentration of treponemes $105 / \mathrm{ml}$} & \multicolumn{2}{|c|}{ Concentration of treponemes $104 / \mathrm{ml}$} \\
\hline & $\begin{array}{l}\text { Mean }(S E M) * \text { days } \\
\text { induration }+ \text { erythema } \\
\text { first appeared }\end{array}$ & $\begin{array}{l}\text { Sites positive/ } \\
\text { inoculated }\end{array}$ & $\begin{array}{l}\text { Mean }(S E M) * \text { days } \\
\text { induration }+ \text { erythema } \\
\text { first appeared }\end{array}$ & $\begin{array}{l}\text { Sites positive/ } \\
\text { inoculated }\end{array}$ \\
\hline $\begin{array}{l}\text { NRS } \\
\text { NRS-HA } \\
\text { NRS-CS } \\
\text { IRS } \\
\text { IRS-HA } \\
\text { IRS-CS }\end{array}$ & $\begin{array}{l}11.6(0.8) \\
11.0(0.5) \\
11 \cdot 3(0.9) \\
20.8(3 \cdot 7) \\
20.5(1 \cdot 1) \\
21.6(1 \cdot 6)\end{array}$ & $\begin{array}{l}16 / 16 \\
16 / 16 \\
16 / 16 \\
16 / 16 \\
14 / 16 \\
14 / 16\end{array}$ & $\begin{array}{l}16 \cdot 8(2 \cdot 6) \\
16 \cdot 0(1 \cdot 2) \\
17.9(0 \cdot 9) \\
27 \cdot 1(1 \cdot 3) \\
25 \cdot 1(2 \cdot 8) \\
24 \cdot 0(2 \cdot 7)\end{array}$ & $\begin{array}{r}16 / 16 \\
16 / 16 \\
16 / 16 \\
5 / 16 \\
5 / 16 \\
3 / 16\end{array}$ \\
\hline
\end{tabular}

*Standard error of the mean for 16 lesions/group.

NRS = Normal rabbit serum. 
organisms with hyaluronic acid or chondroitin sulphate did not affect these antibody reactions. Readings almost identical to those for the two controls were recorded.

TPI tests were performed using organisms harvested from animals not previously exposed to cortisone. As acid BSA positive material was not seen on the surface of these organisms, they were not centrifuged at high speed before testing. Serum samples were prepared from eight different rabbits that had been infected three to 24 months previously. TPI titres were estimated in the presence of hyaluronic acid or chondroitin sulphate $250 \mathrm{mg} / \mathrm{l}$, or medium alone. As shown in table IV, both glycosaminoglycans interfered with immobilisation by immune rabbit serum. Hyaluronic acid decreased TPI titres in each of the eight samples; chondroitin sulphate decreased TPI titres in seven of eight samples. Hyaluronic acid was thus slightly more inhibitory than chondroitin sulphate.

TABLE IV Effect of hyaluronic acid and chondroitin sulphate on complement dependent immobilisation of $T$ pallidum by immune rabbit serum as measured by the TPI test

\begin{tabular}{llll}
\hline \multirow{2}{*}{$\begin{array}{l}\text { Immune } \\
\text { serum } \\
\text { samples }\end{array}$} & \multicolumn{2}{l}{ Treponema pallidum immobilisation test titre* } \\
\cline { 2 - 4 } & Control & $\begin{array}{l}\text { Hyaluronic } \\
\text { acid }\end{array}$ & $\begin{array}{l}\text { Chondroitin } \\
\text { sulphate }\end{array}$ \\
\hline 1 & $1 / 821$ & $1 / 38$ & $1 / 74$ \\
2 & $1 / 810$ & $1 / 257$ & $1 / 374$ \\
3 & $1 / 928$ & $1 / 567$ & $1 / 679$ \\
4 & $1 / 748$ & $1 / 103$ & $1 / 132$ \\
5 & $1 / 645$ & $1 / 161$ & $1 / 763$ \\
6 & $1 / 645$ & $1 / 323$ & $1 / 387$ \\
7 & $1 / 821$ & $1 / 264$ & $1 / 359$ \\
8 & $1 / 165$ & $1 / 103$ & $1 / 66$ \\
\hline
\end{tabular}

*Highest dilution at which $50 \%$ of the treponemes were immobilised.

Interpretation of the TPI test is based on the degree of treponemal immobilisation after incubation for 16 hours. In modified immobilisation experiments, motility was seen for longer periods using different concentrations of immune rabbit serum, and using treponemes harvested from rabbits treated with cortisone. Treponemes were incubated with $50 \%$ normal rabbit serum, $40 \%$ normal and $10 \%$ immune rabbit serum, $25 \%$ normal and $25 \%$ immune rabbit serum, and $50 \%$ immune rabbit serum with and without hyaluronic acid $250 \mathrm{ml} / \mathrm{l}$. Table $\mathrm{V}$ shows the averages of four separate experiments listing the time required to attain $50 \%$ motility $\left(\mathrm{T}_{50}\right)$. Hyaluronic acid alone did not dramatically affect treponemal motility; in 50\% normal rabbit serum without hyaluronic acid the $T_{50}$ was 32 hours, and with hyaluronic acid it was 38 hours $(0 \cdot 21$-fold increase). At each concentration of immune rabbit serum hyaluronic acid interfered with immobilising activity (1.49 to $3 \cdot 64$-fold increases).

TABLE V Effect of hyaluronic acid on complement dependent immobilisation of $T$ pallidum by immune rabbil serum as measured by modified TPI test

\begin{tabular}{lllll}
\hline \multirow{2}{*}{$\begin{array}{l}\text { Concentration (\%) } \\
\text { of immune serum }\end{array}$} & \multicolumn{2}{c}{ Mean $(S E M) * h$ to $50 \%$ motility } & \\
\cline { 2 - 3 } & Control & Hyaluronic acid & Increase + \\
\hline 0 & 32 & $(6)$ & $383 / 4(10)$ & $0 \cdot 21$-fold \\
10 & $51 / 3(3 / 4)$ & 18 & $(4)$ & $2 \cdot 40$-fold \\
25 & $63 / 4(2)$ & $163 / 4(53 / 4)$ & $1 \cdot 49$-fold \\
50 & $43 / 4(1)$ & $213 / 4(71 / 4)$ & $3 \cdot 64$-fold \\
\hline
\end{tabular}

*Standard error of the mean for four experiments.

tHyaluronic acid -1 .

$$
\text { control }
$$

Immobilising antibodies are initially detectable 30 days after infection. ${ }^{29}$ We have recently modified the TPI reaction, and have been able to show serum immobilising antibodies as early as 14 days after infection (unpublished observation). The effects of hyaluronic acid $250 \mathrm{mg} / \mathrm{l}$ were then assessed in this modified TPI reaction. Three different serum samples were isolated from rabbits 14 days after testicular infection. Table VI summarises the results of three experiments in the presence of complement (unheated) and in the absence of complement (heated); data indicate the time required for treponemal motility to decrease to $50 \%$. Without complement the $T_{50}$ was similar in both the control and in the hyaluronic acid preparations. With complement the $T_{50}$ was 15 hours in the control compared with $36 \frac{1}{3}$ hours in the hyaluronic acid preparations (a $2 \cdot 42$-fold increase).

\section{Discussion}

The electron micrographs of von Schmerold and Deubner ${ }^{8}$ and Swain 9 first suggested that $T$ pallidum had a structure like a capsule. Further research

TABLE VI Effect of hyaluronic acid on complement dependent immobilisation of $T$ pallidum by day 14 rabbit serum* as measured by modified TPI test

\begin{tabular}{|c|c|c|c|c|}
\hline \multirow[b]{3}{*}{ Experiment } & \multicolumn{4}{|c|}{ Hours to $50 \%$ motility $\left(T_{50}\right)$} \\
\hline & \multicolumn{2}{|l|}{ Control } & \multicolumn{2}{|c|}{ Hyaluronic acid } \\
\hline & Unheated & Heated $\uparrow$ & Unheated & Heated $t$ \\
\hline $\begin{array}{l}1 \\
2 \\
3 \\
\text { Mean }(\mathrm{SEM}) \neq\end{array}$ & $\begin{array}{l}14 \\
6 \\
25 \\
15(51 / 2)\end{array}$ & $\begin{array}{l}59 \\
134 \\
133 \\
108^{2 / 3}\left(24^{3 / 4}\right)\end{array}$ & $\begin{array}{l}29 \\
29 \\
51 \\
361 / 3(71 / 3)\end{array}$ & $\begin{array}{l}67 \\
145 \\
120 \\
1102 / 3(23)\end{array}$ \\
\hline
\end{tabular}

*Isolated 14 days after intratesticular inoculation of $3 \times 10^{7}$ organisms/ml.

+Complement source inactivated at $56^{\circ} \mathrm{C}$ for 30 minutes.

\#Standard error of the mean for three experiments. 
showed glycosaminoglycans associated with its surface: Zeigler et al used ruthenium red and transmission electron microscopy, ${ }^{11}$ Fitzgerald et al used ruthenium red and scanning electron microscopy; ${ }^{10}$ and Fitzgerald et al used acid BSA and dark field microscopy. ${ }^{12} 13$ These observations have been confirmed using CPC as an alternative technique to show the glycosaminoglycans. Each of these techniques gave identical findings of surface variability. Some organisms were heavily coated with a uniform layer, others showed a patchy distribution, and still others did not contain detectable glycosaminoglycans.

Glycosaminoglycans were removed by high speed centrifuging, which indicated that they were loosely bound to the treponemal surface. This confirmed the findings of Alderete and Baseman in which certain rabbit proteins were loosely bound to the surface of treponemes. ${ }^{30}$ The addition of hyaluronic acid or chondroitin sulphate resulted in their immediate adherence to $T$ pallidum. This occurred with both viable and heat inactivated organisms. Adherent glycosaminoglycans gradually dissipated from the treponemal surface over a period of 72 hours. This may have been the result of degradation by treponemal hyaluronidase, ${ }^{13} 31$ or may reflect the relatively high solubility of these compounds in water.

The origin of the glycosaminoglycans associated with treponemes in freshly harvested preparations is unknown. Small amounts were found four and seven days after infection, and much larger amounts more than 10 days after infection. Two possible explanations follow. Firstly $T$ pallidum may synthesise a glycosaminoglycan capsule. Numerous other bacteria possess capsules, and in many cases capsular material becomes prominent only during late logarithmic stages of growth in vitro. The capsule of $T$ pallidum may become apparent only after extended growth in vivo. Secondly, the glycosaminoglycans may result from passive sticking of rabbit testicular tissue components. The relatively large amounts of hyaluronic acid present within this tissue are tightly bound to proteins, ${ }^{28}$ and therefore may not be able to bind to the treponemal surfaces. $T$ pallidum may possess an enzyme that specifically degrades the rabbit hyaluronic acid and protein complex. As treponemes continued to multiply more hyaluronic acid would be liberated and would eventually uniformly coat treponemal surfaces.

All of the experiments except the TPI reactions (table IV) were performed with treponemes that had been maintained intratesticularly for three years in rabbits treated with cortisone. This procedure may alter the surface composition of $T$ pallidum, as suggested by the results in table II. Treponemes from animals not injected with cortisone during infection showed slightly reduced amounts of glycosaminoglycans associated with their surfaces. In the earlier experiments of Zeigler et al ruthenium red positive glycosaminoglycans were shown using treponemes isolated from animals not treated with cortisone. ${ }^{11}$ The acid BSA technique is relatively crude in showing glycosaminoglycans. Larger quantities associated with the organisms might have been seen using the more refined technique of ruthenium red or CPC and electron microscopy. Most importantly, increasing amounts of glycosaminoglycans are associated with $T$ pallidum as infection progresses.

The question remains as to the role of glycosaminoglycans associated with treponemes in the infectious process. These agents do affect host defence mechanisms. Hyaluronic acid inhibits macrophage phagocytosis and lymphocyte mediated cytolysis ${ }^{32} 33$; it also stimulates polymorphonuclear leucocyte phagocytosis, chemotaxis, and random migration, and it suppresses $\mathrm{T}$ lymphocyte function. ${ }^{34}{ }^{35} \mathrm{Our}$ findings that pathogenic treponemes bound hyaluronic acid and chondroitin sulphate and nonpathogenic treponemes did not, related binding to pathogenicity. The early events in syphilitic infection, before the appearance of lesions, were not affected by glycosaminoglycans associated with the surface of treponemes. Virulence was unchanged when treponemes were coated with varying amounts of hyaluronic acid or chondroitin sulphate and then injected intradermally. The incubation periods, the total sites developing lesions, and progression of lesions were identical with coated and uncoated organisms.

Treponemal glycosaminoglycans may play a part later in infection after lesions begin to develop and host defences have been sufficiently stimulated. At that time, early appearing antibodies are treponemicidal in conjunction with complement (unpublished observation). Mucoid material, which partly consists of hyaluronic acid, accumulates within lesions then. ${ }^{6}{ }^{25-27}$ In the study reported here the hyaluronic acid and chondroitin sulphate did not interfere with the antibody reactions independent of complement involving neutralisation or radioimmunoassay (heat inactivated serum). Thus the antibodies for these two reactions were able to penetrate the treponemal coating of glycosaminoglycans. Edwards et al showed that the polysaccharide capsule of streptococci, which is hyaluronic acid, inhibited the activation of complement. ${ }^{36}$ Chang and Boackle showed that hyaluronic acid inhibited complement dependent haemolysis of sensitised red blood cells; they concluded that hyaluronic acid was a potent anticomplementary factor. Experiments are in 
progress to ascertain whether a similar mechanism may explain the glycosaminoglycan interference with the complement dependent immobilisation of $T$ pallidum.

We thank Anne Utyro for her expert technical help. This research was supported by Public Health Service, National Institute of Allergy and Infectious Diseases grants AI16585 and AI12601, and by World Health Organisation grant V3/181/26.

\section{References}

1. Bishop NH, Miller JN. Humoral immunity in experimental syphilis. II. The relationship of neutralizing factors in immune serum to acquired resistance. J Immunol 1976;117:197-207.

2. Christiansen S. Protective layer covering pathogenic treponemata. Lancet 1962; i:423-5.

3. Hardy PH, Nell EE. Study of the antigenic structure of Treponema pallidum by specific agglutination. American Journal of Hygiene 1957;66:160-72.

4. Metzger M, Hardy PH, Nell EE. Influence of lysozyme upon the treponeme immobilization reaction. American Journal of Hygiene 1961; 73:236-44.

5. Miller JN. Development of an experimental syphilis vaccine. Med Clin North Am 1972;56:1217-20.

6. Turner TB. Syphilis and the treponematoses. In: Mudd S, ed. Infectious agents and host reactions. Philadephia: WB Saunders, 1970:346-90.

7. Turner TB, Hollander DH. Biology of the treponematoses. WHO Monogr Ser 1957; No 35: 1-277.

8. Von Schmerold W, Deubner B. Elektron-enmikroskapische untersuchungen an Reiter-spirochaetales und NicholsTreponemen. Hautarzt 1954;5:511-3.

9. Swain RHA. Electron microscopic studies of the morphology of pathogenic spirochaetes. Journal of Pathology and Bacteriology 1955;69:117-28.

10. Fitzgerald TJ, Cleveland P, Johnson RC, Miller JN, Sykes JA Scanning electron microscopy of Treponema pallidum (Nichols strain) attached to cultured mammalian cells. J Bacteriol 1976; 130: 1333-44.

11. Zeigler JA, Jones AM, Jones RH, Kubica KM. Demonstration of extracellular material at the surface of pathogenic $T$ pallidum cells. British Journal of Venereal Diseases 1976;52:1-8.

12. Fitzgerald TJ, Johnson RC. Surface mucopolysaccharides of Treponema pallidum. Infect Immun 1979;24:244-51.

13. Fitzgerald TJ, Johnson RC. Mucopolysaccharidase of Treponema pallidum. Infect Immun 1979;24:261-86.

14. Laurent TC, Ogston AG. The interaction between polysaccharides and other macromolecules. IV. The osmotic pressure of mixtures of serum albumin and hyaluronic acid. Biochem J 1963;89:249-53.

15. Livermore BP, Johnson RC. Lipids of the spriochaetales: comparison of the lipids of several members of the genera Spirochaeta, Treponema, and Leptospira. J Bacteriol 1974; 120:1268-73.

16. Johnson RC, Eggebraten LM. Fatty acid requirements of the Kazan 5 and Reiter strains of Treponema pallidum. Infect Immun 1971; 3:723-6.

17. Grossfield $H$. Studies on the production of hyaluronic acid in tissue culture. The presence of hyaluronidase in embryo extract. Exp Cell Res 1958;14:213-6.
18. Ibrahim AM, Streitfeld MM. The microassay of hyaluronic acid concentration and hyaluronidase activity by capillary turbidity (CT) and capillary turbidity reduction (CTR) tests. Anal Biochem 1973;56:428-34.

19. United States Department of Health, Education, and Welfare, Public Health Service. Manual of tests for syphilis. Atlanta, Georgia: National Communicable Disease Center, 1964.

20. Zeltzer PM, Pepose JS, Bishop NH, Miller JN. Microassay for immunoglobulin $\mathrm{G}$ antibodies to Treponema pallidum with radioiodinated protein A from Staphylococcus aureus: immunoglobulin $\mathrm{G}$ response in experimental syphilis in rabbits. Infect Immun 1978;21: 163-70.

21. Pepose JS, Bishop NH, Feigenbaum S, Miller JN, Zeltzer PM The humoral immune response in rabbits infected with Treponema pallidum. Sex Transm Dis 1980;7:125-9.

22. Sykes JA, Moore EB. A simple tissue culture chamber. Tex Rep Biol Med 1960; 18:288-97.

23. Fitzgerald TJ, Repesh LA, Oakes SG. Morphological destruction of cultured cells by the attachment of Treponema pallidum. British Journal of Venereal Diseases 1982;58:1-11.

24. Schiller S, Slover GA, Dorfman A. A method for the separation of acid mucopolysaccharides: its application to the isolation of heparin from the skin of rats. J Biol Chem 1961; 236:983-7.

25. Scott V, Dammin GJ. Hyaluronidase and experimental syphilis. III. Metachromasia in syphilitic orchitis and its relation to hyaluronic acid. American Journal of Syphilis, Gonorrhea and Venereal Diseases 1950;34:501-14.

26. Scott V, Dammin GJ. Morphologic and histochemical sequences in syphilitic and tuberculous orchitis in the rabbit. American Journal of Syphilis, Gonorrhea and Venereal Diseases 1954;38: 189-202.

27. Turner TB, Hollander DH. Studies on the mechanism of action of cortisone in experimental syphilis. American Journal of Syphilis, Gonorrhea and Venereal Diseases 1954;38:371-87.

28. Johnson $\mathrm{AD}$, Gomes WR, Vandemark NL. In: The testes. New York: Academic Press, 1970: 1-684.

29. Miller JN. The appearance and persistence of VDRL, RPCF and TPI antibody during the course and treatment of experimental syphilis in the rabbit. $J$ Invest Dermatol 1964;42: 367-71.

30. Alderete JF, Baseman JB. Surface associated host proteins on virulent Treponema pallidum. Infect Immun 1979; 26: 1048-56.

31. Fitzgerald TJ, Gannon EM. Further evidence for hyaluronidase activity of Treponema pallidum. Can $J$ Microbio 1983;29:1507-13.

32. Forrester JV, Balazs EA. Inhibition of phagocytosis by high molecular weight hyaluronate. Immunology 1980;40:435-46.

33. McBride WH, Bard JL. Haluronidase-sensitive haloes around adherent cells. Their role in blocking lymphocyte-mediated cytolysis. J Exp Med 1979; 149:507-16

34. Chevrier A, Gerard N, Delpech B, Gilbert D. Inhibition of active rosette forming T-lymphocytes by hyaluronic acid. Evidence of a receptor for hyaluronic acid on a lymphocyte subpopulation. Biomedicine 1982; 36: 100-3.

35. Hakansson $L$, Hallgren $R$, Venge $P$. Regulation of granulocyte function by hyaluronic acid. In vitro and in vivo effects on phagocytosis, locomotion, and metabolism. J Clin Invest 1980;66:298-305.

36. Edwards MS, Nicholson-Weller A, Baker CJ, Kasper DL. The role of specific antibody in alternative complement pathway mediated opsonophagocytosis of Type III group B streptococcus. J Exp Med 1980; 151: 1275-87.

37. Chang NS, Boackle RJ. Conformational transition of hyaluronic acid is critical to the complement hemolytic inhibitory effect. Fed Proc 1983; 42: 1236. 